\title{
A Global View of Internationalisation: What Next?
}

\author{
Elspeth Jones and Hans de Wit
}

The International Association of Universities has long espoused a values-driven approach to internationalisation "to ensure that the outcomes of internationalisation are positive and of reciprocal benefit to the higher education institutions and the countries concerned" (IAU 2012). In line with this, there is increasing discussion about whether the concept of internationalisation has yet been adopted in more distinctive forms in different parts of the world to better reflect local needs and priorities. This debate seeks to consider the impact on policy and practice through new perspectives from those whose voices do not normally have a strong presence in the discourse. In this contribution, we will reflect further on these key points, and consider what might be involved in taking the internationalisation agenda forward in more sustainable, equitable and inclusive ways.

Rather than simply mimicking Anglo-Western, and predominantly Englishspeaking, approaches, the need for higher education to address global societal challenges, summarised in the Sustainable Development Goals of the United Nations (SDGs), implies a global response. Balancing and integrating local needs with global demands and cross-border working is a major challenge for higher education institutions in the context of ongoing massification, on the one hand, and the demand for a global knowledge economy, on the other.

The rapid changes in international higher education have only increased in range and complexity over the past decade, and not least in response to the global pandemic of 2020. Certainly, the world is facing strong threats to the underlying values of cooperative internationalisation and to achieving the SDGs. Populism, nationalism, xenophobia, and parochial politics are on the increase around the world, presenting

\footnotetext{
E. Jones (ه)

Leeds Beckett University, Leeds, UK

e-mail: e.jones@leedsbeckett.ac.uk

H. de Wit

Boston College, Chestnut Hill, MA, USA

e-mail: dewitj@bc.edu
} 
challenges for those who view internationalisation as more than simply a neoliberal or market-driven concern, and who call for a more inclusive, nuanced, values-driven and comprehensive approach.

A range of countries is emerging as important challengers to the dominance of western internationalisation discourse. But at the same time, there is still a trend towards homogenisation of activities, approaches, policies and strategies. Internationalisation strategies of low- and middle-income countries largely copy the western paradigm in focusing strongly on mobility, reputation and branding, and on SouthNorth relations. This is, to a great extent, driven by economic rationales, increased competitiveness, and dominance of the western university model. Rankings exacerbate this, along with the numerical indicators used to measure internationalisation: numbers of international students, international scholars, mobile students and staff, number of internationally co-authored publications. These indicators tend to drive governments and institutional leaders in higher education to focus (a) on increasing these quantitative targets, and (b) on policies for realising them, such as teaching in English, tuition-fee policies, exclusive focus on research, and so on. Little space is left for innovative ideas around internationalisation, embedded in the local and institutional context.

A strategic approach to International Higher Education (IHE) is of critical importance in advancing knowledge-based societies and for sustainable national development. However, despite this awareness, very few countries in the Global South have such policies in place, approaching IHE in more piecemeal and uncoordinated ways. Reasons include issues around colonial histories, economies, political turmoil, civil conflict and so on, resulting in the perpetuation of tensions between indigenisation and globalisation, with resistance towards imported international perspectives.

\section{A More Nuanced Approach to Internationalisation}

In the past, we have argued for a more nuanced approach to the interpretation and delivery of internationalisation in a globalised context than has hitherto been the case and suggested a range of factors that should be taken into account. Differentiated local and regional responses are required according to geographical variation in social and economic needs. It is also crucial to take into account ethical issues in global engagement and sustainability of practice, including careful consideration of the local context and culture when engaging in cross-border activity.

We have also argued that a globalised view of internationalisation demands political and economic rationales are put into context by (a) measuring the things which are important, not simply those which can be measured, (b) learning from partners and diversity of policy, practice and research around the world, (c) understanding the transformational potential of internationalisation for all - students, faculty and support staff - and its link with employability and citizenship. This means prioritising the intercultural as well as the international through curriculum, teaching and learning at home, not only through mobility. 
Yet, internationalisation continues to both reflect and exacerbate the inequalities in global societies. Access to higher education is still only available to a small proportion of the global population, and travelling to study in another country for short or longer periods will always be the preserve of a relatively wealthy, middle-class elite.

The prevailing result of institutional internationalisation strategies which predominantly focus on mobility will be inequality of access, opportunity and outcomes. Sadly, this focus continues to be the dominant paradigm as far as many institutional leaders are concerned. With such limited numbers taking part, mobility can neither solve the growing demands by employers for graduates able to work across countries and cultures nor will it enable local knowledge and contexts to contribute to solving major global issues, such as those highlighted in the SDGs.

\section{Aligning Internationalisation with Human Values and the Common Global Good}

The importance of internationalising the curriculum 'at home' has never been more vital than in the current cultural, economic, social, and political climate, not least because cultural diversity in local populations is increasingly prevalent, with intercultural engagement as part of personal and professional life becoming progressively the norm. However, institutions in the Global North and South are failing to take curriculum internationalisation forward in a way which will embed it more deeply in strategic plans.

Institutional and academic silos work against the need to be more comprehensive and integrated in our approach to internationalisation. Too often it is seen as the role of the international office to deliver an internationalisation agenda principally focused on mobility and income generation, rather than shared human values and the common global good. Moving from the 'success box' of internationalisation requires us to address assumptions and perceptions of what it means to be international, for our institutions and for ourselves. This can mean uncomfortable and challenging debates and may require fundamentally re-thinking our approach to international engagement, bringing it more in line with the institution's broader societal role.

The SDGs may offer a new framework within which the social role and responsibility of higher education internationalisation could evolve. Institutional internationalisation strategies focus overwhelmingly on recruiting international students, on building partnerships according to self-interest for impact at home or abroad through an enhanced international reputation, and on research with the greatest potential to raise both individual and institutional status. Egron-Polak and Marmolejo (2017) point out that this marginalises institutions' existing good work in international capacity building, curriculum internationalisation, global citizenship development, sustainability of lifestyles and the economy, development of health policies and practice, teacher training and so on, which offer more significant contributions to society and achievement of the SDGs. 
Indeed, these reflections are also behind the concept of Internationalisation of Higher Education for Society (IHES), which seeks to align the international and social responsibility dimensions of institutional strategy.

\section{Internationalisation for Society}

In addition to the capacity-building aspects of an institution's international engagement, other thematic examples of the role of higher education internationalisation in wider society include its contribution in relation to refugees and migration and the enhancement of social inclusion. It also needs to be seen in the context of all levels of education in order to be inclusive of as wide a population as possible.

With regard to what has been termed the 'forced internationalisation' of migrants and refugees (Streitwieser et al. 2017) view reception and support of these populations as being an important part of HE internationalisation frameworks and global engagement. Such an understanding, they argue, will not only solve the immediate problems of the individuals concerned but will also help to ensure those individuals have the skills and knowledge needed to facilitate reconstruction when political security has returned. This role can be connected to broader issues of global stability in the short and longer-term, enabling higher education to make a valuable contribution to post-conflict recovery.

Internationalisation as a means of enhancing social inclusion, as a contribution to social responsibility and the development of global citizenship is an increasingly present interest in many parts of the world. This is particularly true in developing countries, where higher education appears to show a more focused acknowledgement of the social mission of universities than elsewhere. In the developed world, the notion of 'society' has become more market-focused, and terms such as 'workforce development' and 'employability' dominate the agenda of higher education and its internationalisation.

To realise key societal objectives, it would seem obvious to suggest that internationalisation should be fundamental to education at all levels. Yet, until fairly recently, internationalisation in primary and vocational education has been largely ignored in spite of having evolved substantially. Internationalisation is not the exclusive domain of higher education and can only reach full potential if it is aligned with and built on other levels of education, emphasising social and individual inclusion in the process.

\section{What Next?}

Far from becoming globalised in the sense of homogenisation, our view is that internationalisation strategy across geographical contexts continues to develop beyond traditional understandings. Engaging with the different political, economic, social, and historical factors in regional settings can offer new insights for those who choose 
not to imitate Anglo-western models. In other words, how can institutions operate successfully in their local, national, and regional environments, making a meaningful and responsible contribution to the society they are part of, while also meeting internationalisation objectives? Will they take a competitive direction or the route towards a more socially-responsible approach?

As the COVID-19 pandemic has made obvious, the competitive route is difficult, requires substantial public and private investment, and can increase the social divide, especially where student mobility retains its primary focus. For some countries in the Global South, the interplay between globalisation, regionalisation and nationalisation may be complex, with the potential to highlight harmful effects of internationalisation resulting in its possible rejection. Delicate discussions around de-colonisation, de-racialisation and de-imperialisation may be more important in these contexts than internationalisation itself. However, nationalisation (or regionalisation) and internationalisation are two sides of the same coin. A total focus on nationalisation or regionalisation would mean isolation while exclusively concentrating on internationalisation would imply ongoing dependency and copying of Western approaches to internationalisation, not embedded in the local context.

A more socially-responsible route is not easy either, and also requires substantial public and private resources, but it is more socially inclusive and, in the long run, will result in a tertiary education sector with higher quality. This approach implies paying greater attention to internationalisation of the curriculum at home. It should align with other levels of education and better address the international dimensions of social responsibility.

So, to return to our question, what next for internationalisation as a global phenomenon? This question is even more fundamental in the current context, with the challenges of a pandemic, Black Lives Matter, nationalism and populism, along with a severe global economic crisis and climate emergency. In our view, internationalisation cannot continue to be driven primarily by competitive economic rationales. It has to find the right balance between local, national, regional and global needs and objectives. It has to work towards achieving the Sustainable Development Goals of the United Nations. It must respect local identities, cultures and languages. Mobility, for qualifications or credit, has to be downgraded as the focus of internationalisation strategies, in the interest of sustainability and inclusivity as well as environmental concerns. Global and intercultural learning for all has to be at the centre of strategies and policies, facilitated in part through the opportunities presented by technological innovation, and replacing the emphasis on mobility for the elite minority.

It is crucial that we take account of different contexts in our understanding and approach, considering internationalisation in a more nuanced fashion than before. We have attempted here to further such examination in order to stimulate reflection, understanding, and actions towards innovative, sustainable, ethical, and socially inclusive conceptualisations of internationalisation. 


\section{References}

Egron-Polak, E., \& Marmolejo, F. (2017). Higher Education Internationalization: Adjusting to new landscapes. In H. De Wit., J. Gacel-Ávila., E. Jones., \& N. Jooste. (Eds.), The Globalisation of Internationalisation: Emerging voices and perspectives. London: Routledge.

International Association of Universities. (2012). Affirming Academic Values in Internationalization of Higher Education: A Call for Action. Paris: IAU.

Streitwieser, B., Miller-Idriss, C., \& De Wit, H. (2017). Higher Education's Response to the European Refugee Crisis: Challenges, Strategies, and Opportunities. In H. De Wit, et al. (Eds.), The globalization of internationalization: Emerging voices and perspectives. (pp. 29-39). Taylor \& Francis.

Elspeth Jones is Emerita Professor of the Internationalisation of Higher Education, Leeds Beckett University, UK, and Honorary Visiting Fellow at the Centre for Higher Education Internationalisation, Università Cattolica del Sacro Cuore, Milan. She is founding editor of the book series Internationalization in Higher Education (Routledge) and curator of a YouTube channel, International Educator Conversations. Elspeth has researched and published extensively in the field and has undertaken work for governments, national and international organisations, and universities across five continents.

Hans de Wit is Professor and Former Director of the 'Center for International Higher Education' (CIHE) at Boston College, USA. He is Senior Fellow of IAU. He is a founding member and past president of the European Association for International Education (EAIE). He is Founding Editor of the 'Journal of Studies in International Education' (SAGE), and Consulting Editor of the journal Policy Reviews in Higher Education. He is a leading expert on internationalization of higher education and has written several books and articles on this topic as well as given advice to organizations like OECD, UNESCO, World Bank and European Commission.

Open Access This chapter is licensed under the terms of the Creative Commons Attribution 4.0 International License (http://creativecommons.org/licenses/by/4.0/), which permits use, sharing, adaptation, distribution and reproduction in any medium or format, as long as you give appropriate credit to the original author(s) and the source, provide a link to the Creative Commons license and indicate if changes were made.

The images or other third party material in this chapter are included in the chapter's Creative Commons license, unless indicated otherwise in a credit line to the material. If material is not included in the chapter's Creative Commons license and your intended use is not permitted by statutory regulation or exceeds the permitted use, you will need to obtain permission directly from the copyright holder. 